local neurovascular structures from trauma and resultant postoperative morbidity. Although this procedure carries recognized neurovascular complications, this technique has proved safe and successful in preventing them.

\section{References}

1. McCormack LJ, Caldwell EW, Anson BJ. Brachial and antebrachial arterial patterns. A study of 750 extremities. Surg Gynecol Obstet.. $1953 ; 96: 43-54$
2. Wood SJ, Abrahams PH, Sanudo JR, Ferreira BJ. Bilateral superficial radial artery at the wrist associated with a radial origin of a unilateral median artery. J Anat. 1997;189:691-3.

3. Denton TA, Trento L. Radial artery harvesting for coronary bypass operations: neurologic complications and their potential mechanisms. J Thorac Cardiovasc Surg. 2001;121:951-6.

4. Reyes AT, Frame R, Brodman RF. Technique for harvesting the radial artery as a coronary artery bypass graft. Ann Thorac Surg. 1995;59: 118-20.

5. Singer E. Embryological pattern persisting in the arteries of the arm. Anat Rec. 1933;55:403-9.

\title{
Retrograde segmental aortic repair for type II thoracoabdominal aortic aneurysm
}

Teruhisa Kazui, MD, Katsushi Yamashita, MD, Hitoshi Terada, MD, and Naoki Washiyama, MD, Hamamatsu, Japan

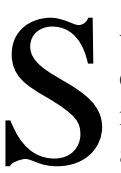

urgical treatment of type II thoracoabdominal aortic aneurysms (TAAAs) is associated with high morbidity and mortality ${ }^{1}$ because the procedure is complicated and adjuncts for spinal cord and visceral protection are required. To this end, a distal aortic perfusion through a left heart bypass has recently been used in type II TAAA repair. ${ }^{2,3}$ We have been using partial femorofemoral bypass as a distal aortic perfusion in the treatment of descending thoracic aortic aneurysms and TAAAs. ${ }^{4,5}$ However, we have became aware that a retrograde perfusion from the femoral artery carries the risk of producing a malperfusion of visceral organs in a chronic aortic dissection. We therefore have modified our technique for this lesion.

\section{Patients and Methods}

Patient data. Five patients with a chronic aortic dissection underwent TAAA repair with the modified technique. They ranged in age from 26 to 65 years with a mean of 49 years. Four patients had a typical Marfan syndrome and had previously undergone cardiovascular operations for a DeBakey type I dissection with aortic root, a total arch, and either proximal descending thoracic replacement or the elephant trunk technique. The remaining patient did not have Marfan syndrome and showed a DeBakey type IIIb dissection. A preoperative aortogram and computed tomographic scanning showed a diffuse aneurysmal formation of the thoraco-

From the First Department of Surgery, Hamamatsu University School of Medicine, Hamamatsu, Japan.

Received for publication Dec 21, 2003; revisions received Jan 13, 2004; accepted for publication Feb 4, 2004.

Address for reprints: Teruhisa Kazui, MD, First Department of Surgery, Hamamatsu University School of Medicine, 1-20-1 Handayama, Hamamatsu, 431-3192 Japan (E-mail: tkazui@ hama-med.ac.jp).

J Thorac Cardiovasc Surg 2004;127:1827-9

$0022-5223 / \$ 30.00$

Copyright $\odot 2004$ by The American Association for Thoracic Surgery doi:10.1016/j.jtcvs.2004.02.003
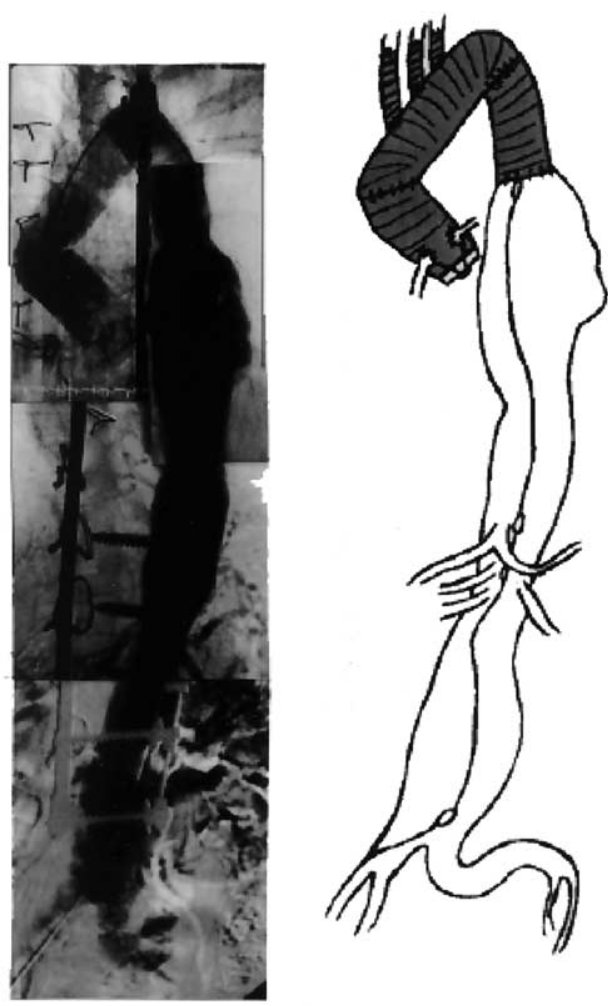

Figure 1. Preoperative aortogram (left) and diagram (right) of patient with Marfan syndrome who had previously undergone aortic root replacement with composite valved conduit, total arch, and proximal descending aortic replacement showing complicated circulatory status of visceral arteries.

abdominal aorta and perfusion of some visceral arteries from the false lumen, suggesting a potential risk of organ malperfusion if a retrograde perfusion were to be used (Figure 1). 


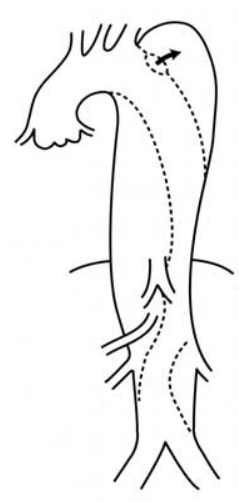

A

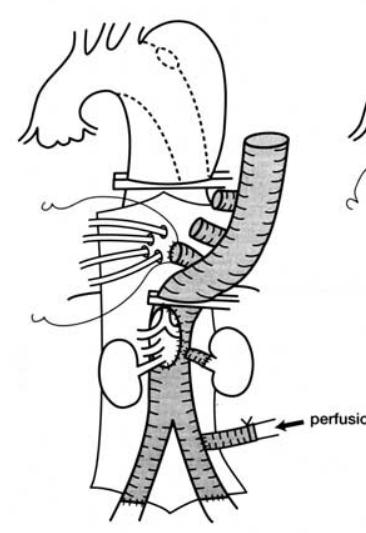

D

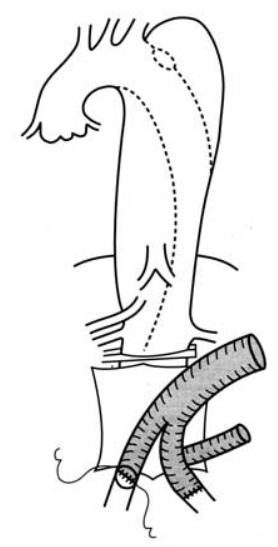

B

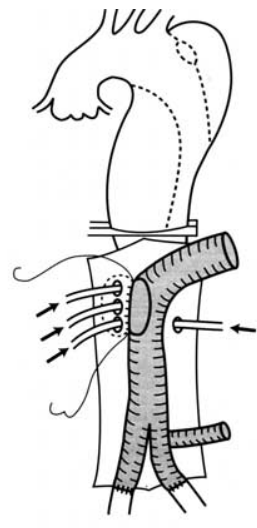

C

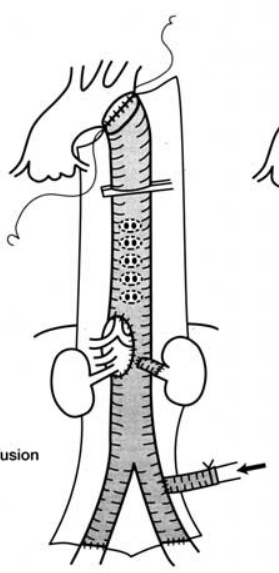

E

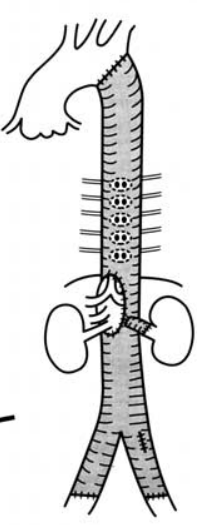

$\mathrm{F}$
Figure 2. Modified type II thoracoabdominal aortic replacement technique in chronic aortic dissection. See text for detail.

Surgical technique. After the patient was fully heparinized, a long venous drainage cannula was inserted into the right atrium through the femoral vein. The infrarenal abdominal aorta and both distal iliac arteries were crossclamped. Next, each distal limb of a Y-shaped, woven Dacron polyester fabric graft was sutured to a corresponding iliac artery (Figure 2, B). The proximal aortic clamp was shifted proximally just below the diaphragm, after which the celiac axis, superior mesenteric, and both renal arteries were cannulated and perfused with a roller pump at a flow rate of 100 $\mathrm{mL} / \mathrm{min}$ for each artery (Figure 2, C). The visceral arteries were reconstructed either by having the celiac axis, superior mesenteric, and right renal arteries attached to the graft, with the left renal artery connected separately, or a by technique in which the visceral arteries were separately implanted with graft interposition. After the visceral arteries were reimplanted, the crossclamp on the graft was moved proximally, restoring perfusion to the visceral organs from a side arm attached to the previously implanted Y-shaped graft (Figure 2,D). Subsequently, the aortic clamp was moved to the descending thoracic aorta, two pairs of the intercostal arteries $\left(\mathrm{T}_{11}, \mathrm{~T}_{12}\right)$ were exposed, and back bleeding from these arteries was put under control with Fogarty balloon catheters. The arteries were reconstructed with side-armed grafts that had already been at-
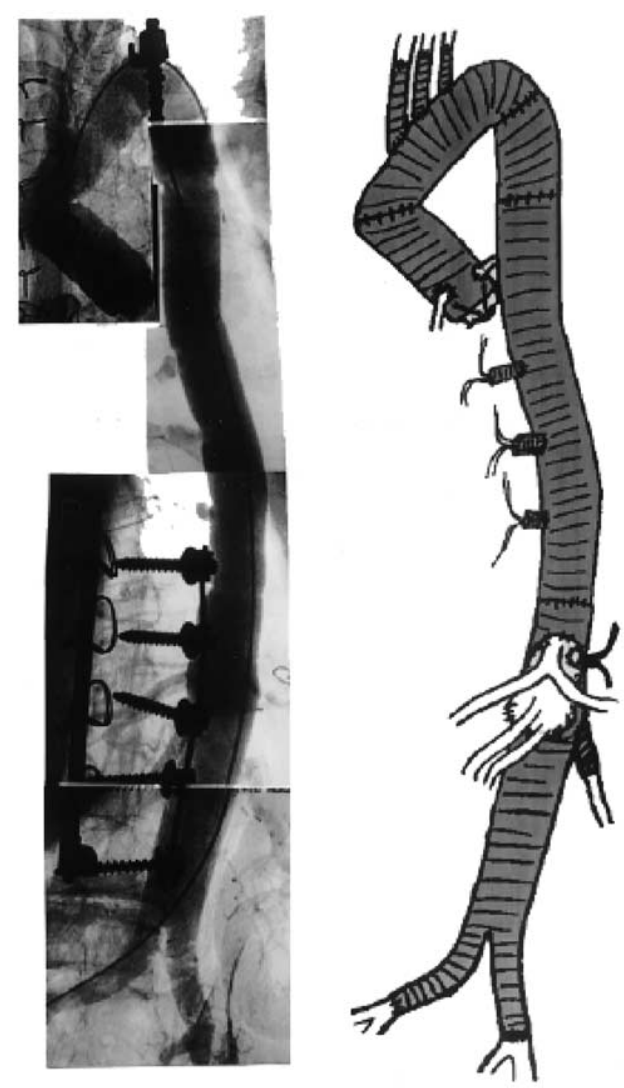

Figure 3. Postoperative aortogram and diagram of same patient as in Figure 1 after type II TAAA repair by retrograde segmental aortic repair technique, showing satisfactory reconstruction of thoracoabdominal aorta, celiac axis, superior mesenteric and both renal arteries, and $T_{9}, T_{10}, T_{11}$, and $T_{12}$ intercostal arteries.

tached to the main graft. After the reconstruction, the clamp on the graft was shifted more proximally to perfuse the reimplanted intercostal arteries. Afterward, two or three pairs of proximal intercostal arteries $\left(\mathrm{T}_{8}, \mathrm{~T}_{9}, \mathrm{~T}_{10}\right)$ were reimplanted in a similar fashion (Figure 2, E). The average number of critical intercostal arteries in the $T_{8}$ to $L_{1}$ range was four for this series. Finally, a proximal graft anastomosis was performed and the operation was completed (Figure 2, F).

\section{Results}

All the patients survived their operations and were discharged from the hospital. With respect to postoperative morbidities, 1 patient who had undergone TAAA repair along with a reimplantation of $\mathrm{T}_{9}, \mathrm{~T}_{10}, \mathrm{~T}_{11}$ and $\mathrm{T}_{12}$ had paraparesis develop, which may have been caused by prolonged hypotension resulting from hemorrhage. Pulmonary failure requiring prolonged respirator support was noted in this case. However, neither renal failure, liver dysfunction, nor intestinal ischemia was present. A postoperative aortogram showed satisfactory reconstruction of the thoracoabdominal aorta and visceral and intercostal arteries (Figure 3). 


\section{Discussion}

We have previously seen a patient with a chronic aortic dissection in whom bowel ischemia with multiple organ failure developed after a conventional antegrade segmental extent type II TAAA repair with the aid of a femorofemoral bypass and a selective visceral perfusion. We speculated that this complication may have been related to a malperfusion of the visceral organ as a result of the retrograde femoral perfusion. Whenever there is any reason to believe that retrograde perfusion from the femoral artery will cause a malperfusion of the abdominal organs, then a segmental aortic repair, starting from the distal aortic side, appears to be a valid alternative in type II TAAA. Profound hypothermic circulatory arrest with antegrade perfusion is an alternative to this method if proximal aortic clamping is not technically feasible.

\section{References}

1. Svensson LG, Crawford ES, Hess KR, Coselli JS, Safi HJ. Experience with 1509 patients undergoing thoracoabdominal aortic operations. $J$ Vasc Surg. 1993;17:357-70.

2. Coselli JS, LeMaire SA. Left heart bypass reduces paraplegia rates after thoracoabdominal aortic aneurysm repair. Ann Thorac Surg. 1999;67:1931-4.

3. Safi HJ, Miller CC, Yawn DH, Iliopoulos DC, Subramaniam M, Harlin $\mathrm{S}$, et al. Impact of distal aortic and visceral perfusion on liver function during thoracoabdominal and descending thoracic aortic repair. $J$ Vasc Surg. 1998;27:145-53.

4. Kazui T, Komatsu S, Yokoyama H. Surgical treatment of aneurysms of the thoracic aorta with the aid of partial cardiopulmonary bypass: an analysis of 95 patients. Ann Thorac Surg. 1987;43:622-7.

5. Kazui T, Komatsu S, Sasaki T, Yamada O. Graft inclusion technique for thoracoabdominal aortic aneurysms involving visceral branches with the aid of a femoro-femoral bypass. J Cardiovasc Surg. 1987;28:663-70.

\section{Resection of a pleomorphic carcinoma of the lung invading the descending aorta}

Yukio Sato, MD, PhD, Noriko Saito, MD, Shunsuke Endo, MD, PhD, Hiroaki Konishi, MD, PhD, Osamu Kamisawa, MD, PhD, Shinichi Otani, MD, Tsuyoshi Hasegawa, MD, and Yasunori Sohara, MD, PhD, Tochigi, Japan

T he concept of pleomorphic carcinoma was introduced by Fishback and colleagues ${ }^{1}$ in a report indicating that most carcinomas with spindle cell or giant cell differentiation are associated with other major subtypes of lung carcinoma, such as squamous cell carcinoma, adenocarcinoma, or large cell carcinoma. In the new World Health Organization/International Association for the Study of Lung Cancer classification system, pleomorphic carcinoma is independent from other major subtypes, and at least a $10 \%$ spindle cell or giant cell component must be present for a diagnosis of pleomorphic carcinoma. ${ }^{2}$ Pleomorphic carcinomas tend to be large, peripheral tumors that often invade the adjacent tissue, ${ }^{1}$ which could pose problems in surgical treatment. Here we present a case of successful resection of pleomorphic carcinoma invading the descending aorta.

\footnotetext{
From the Division of Thoracic Surgery, Department of Surgery, Jichi Medical School, Minamikawachi, Tochigi, Japan.

Received for publication Nov 20, 2003; revisions received Dec 26, 2003; accepted for publication Jan 5, 2004.

Address for reprints: Yukio Sato, MD, PhD, Division of Thoracic Surgery, Department of Surgery, Jichi Medical School, 3311-1 Minamikawachi, Kawachi, Tochigi 329-0498, Japan (E-mail: tcvysato@jichi.ac.jp).

J Thorac Cardiovasc Surg 2004;127:1829-30

$0022-5223 / \$ 30.00$

Copyright (C) 2004 by The American Association for Thoracic Surgery doi:10.1016/j.jtcvs.2004.01.010
}

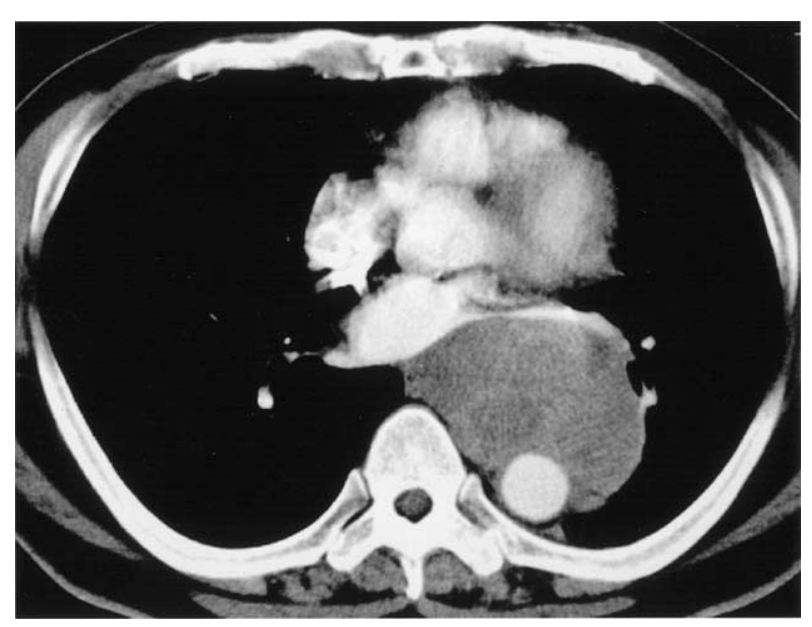

Figure 1. Chest computed tomographic scan shows $9 \times 6 \times$ $10-\mathrm{cm}$ mass enhanced with contrast medium and located in left posterior mediastinum surrounding descending aorta.

\section{Clinical Summary}

A 59-year-old man was admitted to our hospital because of a 3-month history of cough, fever, and back pain. Chest radiography revealed a large mass in the left hilum extending to the posterior mediastinum. Chest computed tomographic scanning (Figure 1) and magnetic resonance imaging revealed a $9 \times 6 \times 10-\mathrm{cm}$ contrast-enhanced mass located in the left posterior mediastinum, surrounding the descending aorta. The contact angle of the tumor to the descending aorta was $270^{\circ}$, and the fat layer between them was not visible. It was therefore suspected that the tumor had 